Universidad de Lima

Escuela de Posgrado

Maestría en Derecho Empresarial

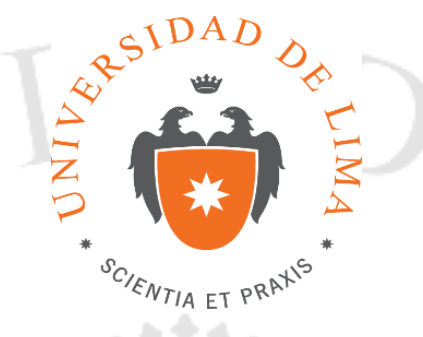

\title{
LAS FIGURAS DEL COMMON LAW USADAS EN LOS CONTRATOS DE COMPRA VENTA DE ACCIONES Y SU RECEPCIÓN POR EL CÓDIGO CIVIL
}

Trabajo de investigación para optar el Grado Académico de Maestro en Derecho

Empresarial

\section{Luis Angel Mejía Servan}

Código 19991265

\author{
Lima - Perú \\ Julio, 2015
}




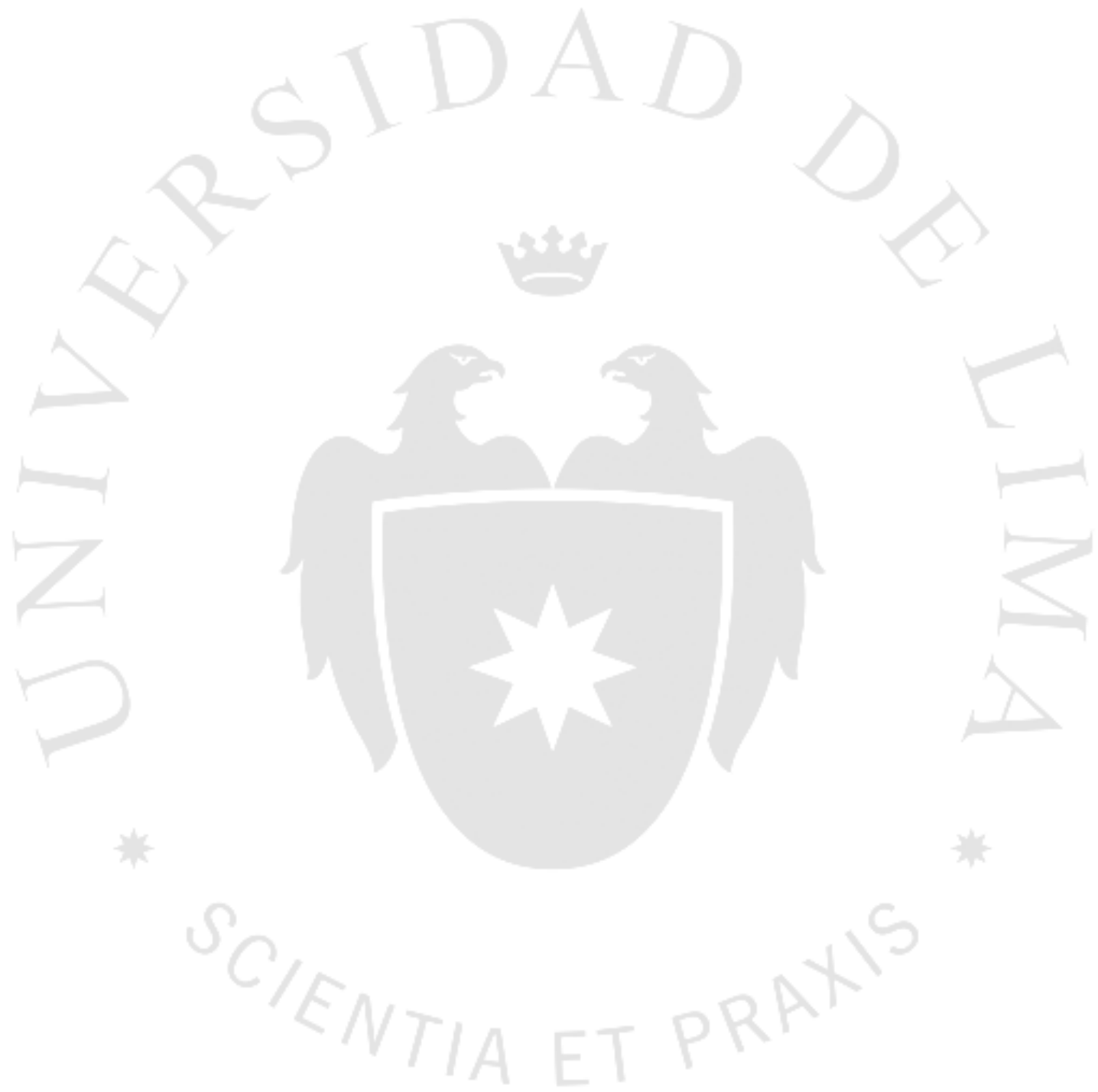




\section{LAS FIGURAS DEL COMMON LAW USADAS EN LOS CONTRATOS DE COMPRA VENTA DE ACCIONES Y SU RECEPCIÓN POR EL CÓDIGO CIVIL}




\section{TABLA DE CONTENIDOS}

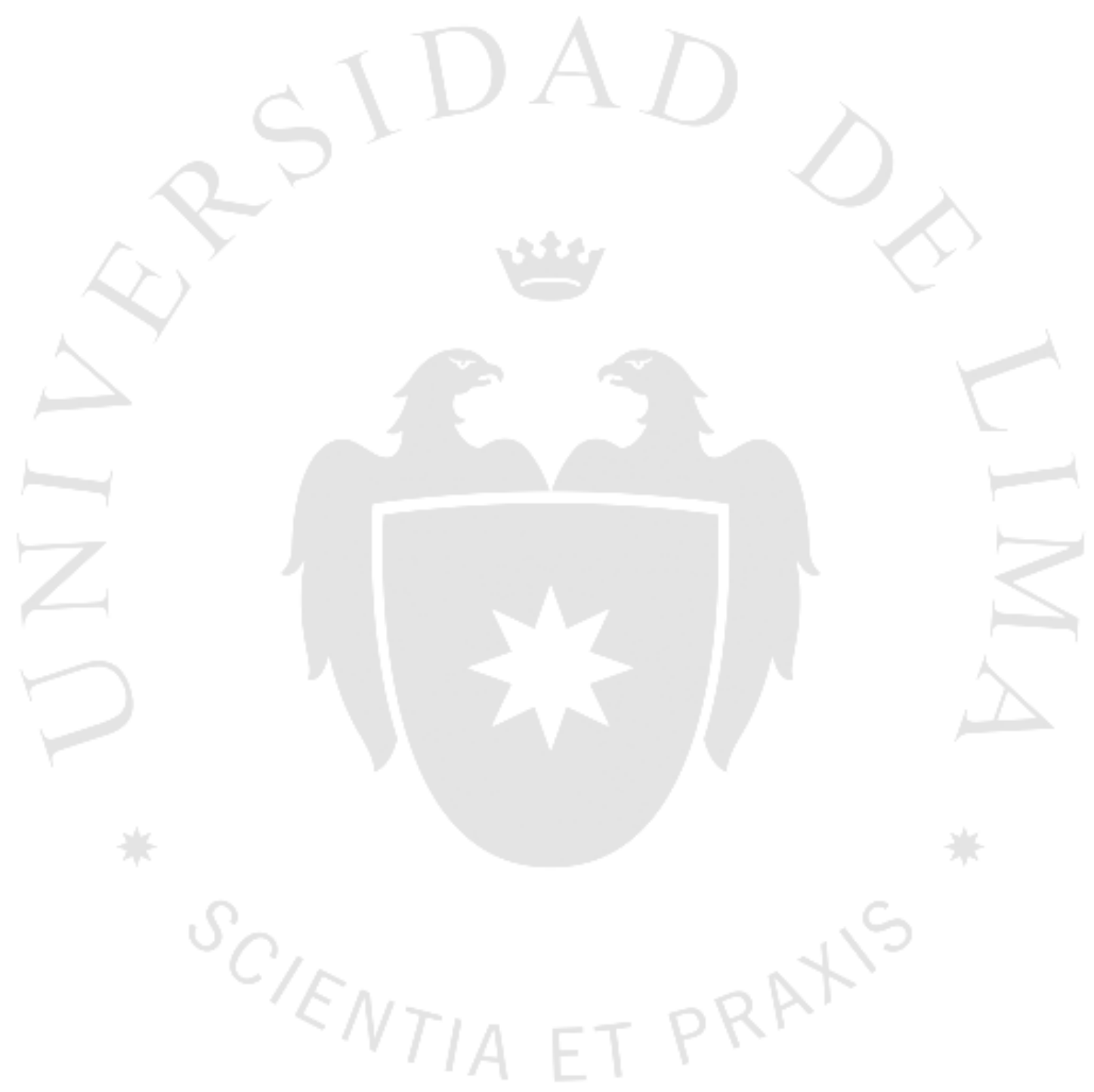




\section{INTRODUCCIÓN}

En el año 2014, el Perú registró 69 operaciones de M\&A ${ }^{1}$ por un monto que exceden los 10 Billones de Dólares ${ }^{2}$. A esa cifra debemos agregarle las operaciones de M\&A que no se reportan por cuestiones de confidencialidad. Dichas cantidades nos demuestra el incremento de las operaciones de M\&A en el mercado peruano. Como consecuencia del incremento de las operaciones de M\&A, los abogados nos hemos visto en la necesidad de incursionar en el uso de nuevas figuras y metodologías contractuales. Hoy en día es muy frecuente estar en contacto con términos como SPA (Share Purchase Agreement), Shareholder Agreement (Pacto de Accionistas), Escrow Account (Cuenta Escrow), Reps and Warranties (Representaciones y garantías), indemnities (Indemnizaciones), entre otros.

Los términos señalados en el párrafo anterior provienen del Common Law el cual es la base sobre la cual descansan las operaciones de M\&A en el Perú. La influencia del Common Law en el Perú se puede deber a que gran parte de los abogados que dirigen los procesos de M\&A en el Perú han ejercido la actividad en Estados Unidos o Inglaterra o también debido a que en el ámbito del Common Law se dan las principales operaciones de M\&A en el mundo, y por ello, es un modelo a seguir.

El uso por parte de los abogados peruanos de las figuras contractuales y metodológicas usadas en el Common Law no es capricho de ellos; todo lo contrario, responden a que en una operación de M\&A no sólo se están adquiriendo las acciones de una sociedad sino además se está adquiriendo los activos de la empresa, los trabajadores, los tributos, las licencias, los procesos judiciales, las signos distintivos, los proveedores, la situación financiera, entre otros aspectos.

El Common Law se rige por los principios de predictibilidad y certidumbre pues se asume que las partes están en capacidad de regular sus relaciones y por ende, el contrato se considera el único documento a través del cual regulan sus relaciones. Siendo así, a

\footnotetext{
${ }^{1}$ Siglas de Mergers \& Acquisitions (En español, fusiones y adquisiciones).

${ }^{2}$ Información obtenida de http://latinlawyer.com/reference/topics/55/jurisdictions/19/peru/
} 
diferencia de la legislación peruana, figuras como la buena fe no son usadas en el Common Law para integrar las relaciones contractuales.

La importación por parte del Perú de conceptos propios del Common Law plantea retos muy importantes a los abogados peruanos pues éstos deben buscar que esos conceptos armonicen con la legislación peruana, la cual se sustenta sobre bases muy distintas a las que se sustenta el Common Law.

La finalidad del presente trabajo es explicar cómo la legislación peruana recibe dos conceptos que han sido importados del Common Law para ser usados, bajo la legislación peruana, en operaciones de compra venta de acciones. El primer punto que se revisará en el presente trabajo es analizar si la violación a la cláusula de declaraciones y garantías cuenta con un remedio específico de acuerdo al Código Civil peruano. El segundo punto que se revisará es si la cláusula de limitación de responsabilidad en caso de falsedad o inexactitud de las declaraciones la cual es usada en el Common Law es válida de acuerdo a la legislación peruana.

En el presente trabajo empezaré comentando sobre la regulación aplicable a un contrato de compra venta de acciones. Luego de ello, se hará una explicación de cómo se estructura un contrato de compra venta de acciones. Seguidamente se explicará en qué consiste las declaraciones y garantías y finalmente se analizarán los remedios que proporciona la legislación peruana a la violación de las declaraciones y garantías y se analizará si la limitación de responsabilidad en cuanto a monto que se suele pactar en una operación de compra venta de acciones es válida. 


\section{CAPÍTULO I: DE LA COMPRA VENTA DE ACCIONES EN EL PERÚ}

\subsection{Marco normativo de la compra venta de acciones}

En el Perú tenemos varios cuerpos normativos que regulan la compra venta de acciones de una sociedad. El primer marco normativo está dado por la Ley General de Sociedad, Ley $\mathrm{N}^{\circ}$ 26887, el cual fija las reglas básicas para la constitución y regulación de una sociedad en cualquiera de sus tipos societarios. Un segundo marco normativo es el Código Civil el cual fija, entre otros, reglas para la compra venta de bienes muebles. Otros cuerpos normativos son la Ley $\mathrm{N}^{\circ} 27287^{\circ}$, Ley de Títulos Valores, y en caso las acciones de la sociedad estén listadas en la Bolsa de Valores, el Decreto Legislativo $\mathrm{N}^{\circ}$ 891, Ley de Mercado de Valores.

De todos los textos normativos señalados, el que resultaría aplicable a un contrato de compra venta de acciones es el código civil pues: a) Es el cuerpo legal que califica a las acciones como bienes muebles ${ }^{3}$ y b) Es el cuerpo legal que tipifica al contrato de compra venta que es el acto jurídico por el cual se transfieren las acciones de una target ${ }^{4}$.

El código civil establece normas imperativas y también normas supletorias. En ocasiones las normas imperativas pueden interferir con algunas estipulaciones establecidas en el contrato de compra venta de acciones y que son propias del Common Law y en otras ocasiones, las normas supletorias del Código Civil pueden no solucionar un conflicto entre las partes o en todo caso, pueden solucionarlo de manera ineficaz.

En el presente trabajo se analizará como recibe el Código Civil peruano a dos figuras que son usadas por el Common Law para regular los contratos de compra venta de acciones. El primero de ellos, es determinar qué remedio da el Código Civil a la violación a

\footnotetext{
${ }^{3}$ Artículo $885^{\circ}$ del Código Civil.- "Son bienes muebles: ...8.- Las acciones o participaciones que cada socio tenga en sociedades o asociaciones, aunque a éstas pertenezcan bienes inmuebles".

${ }^{4}$ Entiéndase por target la empresa cuyas acciones son materia de compra.
} 
la cláusula de declaraciones y garantías. Seguidamente, se analizará si la cláusula de limitación de responsabilidad en caso de falsedad o inexactitud de las declaraciones la cual es usada en el Common Law es válida de acuerdo a la legislación peruana

Antes de analizar lo señalado en el párrafo anterior, se explicará la estructura de un contrato de compra venta de acciones.

\subsection{Del contrato de compra venta de acciones}

A diferencia de la mayoría de operaciones de compra venta, la compra de acciones es una operación compleja que abarca muchos más riesgos de los que tiene por ejemplo una operación de venta de un inmueble. Esa cantidad de riesgos, muchos de ellos imprevisibles, nos lleva a la necesidad de establecer acuerdos contractuales complejos y sofisticados que mitiguen los riesgos tanto para el comprador como para el vendedor.

Como lo dice Payet Puccio (2015):

Ello deriva (refiriéndose a la complejidad de la compra de una empresa), de la naturaleza del objeto mismo de la entidad que es objeto de la transacción. Si bien desde el punto de vista jurídico, la adquisición de una empresa se instrumenta o realiza en la mayoría de los casos a través de la adquisición de acciones, operación que, en abstracto, no tiene nada de complicado, en realidad la complejidad de la entidad "subyacente" a las acciones, la empresa, que es lo que en verdad quiere adquirir el comprador, hace que estas operaciones disten mucho del simple endoso de unos títulos valores o de la mera orden de una sociedad agente de bolsa para ejecutar una compra venta bursátil de acciones. En este tipo de operaciones, la compra de las acciones es solo el medio para adquirir la titularidad última de la empresa. (p. 88)

Por ello, lo que realmente un comprador desea adquirir al comprar acciones son los activos de la target, sus relaciones crediticias, sus relaciones comerciales, sus relaciones laborales, es decir, en realidad no sólo desea adquirir las acciones sino desea adquirir la empresa como conjunto de relaciones jurídicas y económicas. 
Toda esa cantidad de relaciones jurídicas y económicas que implica la adquisición de una empresa, lleva al vendedor y al comprador a la necesidad de regular los riesgos que se presentan en este tipo de operaciones.

Debido a la complejidad antes señalada, la mayoría de contratos de compra venta de empresas suele tener el siguiente clausulado:

a) Cláusula de Definiciones.- En esta cláusula se trata de definir conceptos que serán usados a lo largo del contrato para así hacer más fácil la lectura del contrato.

b) Cláusula de Antecedentes.- Se menciona que los vendedores son accionistas de la empresa target y que el comprador está interesado en adquirir sus acciones.

c) Cláusula del Objeto del Contrato.- Se menciona que el vendedor transfiere sus acciones en la target y el comprador las adquiere por un precio a pagar.

d) Cláusula del Precio y forma de pago.- Se establece el precio de venta y la oportunidad de su pago. En caso el precio de venta sea determinable se establece la manera de calcularlo. Por ejemplo, el precio puede estar en función a un múltiplo del EBITDA o en base al capital de trabajo de la Target.

e) Cláusula de Declaraciones y Garantías.- En esta cláusula se estableces afirmaciones de los vendedores respecto de la situación económica, legal, financiera, contable y operativa de la target. Más adelante se analizará con mayor precisión en qué consisten las declaraciones y garantías.

f) Cláusula de Indemnización por falsedad o inexactitud de una declaración y garantía.- En esta cláusula se establece qué ocurre en caso una de las declaraciones y garantías dadas por el vendedor es falsa o inexacta, soliéndose pactar que en ese caso, el vendedor debe indemnizar al comprador o a la target, según quien sufra el daño.

g) Cláusula de procedimiento de reclamos.- En esta cláusula se establece el procedimiento que deben seguirse en caso el comprador presente algún reclamo al vendedor o en todo caso, en caso se presente un reclamo por un tercero hacia el comprador o hacia la empresa target. Dichos reclamos deben tener su origen en 
actos u omisiones producidos con anterioridad a fecha en que se transfirieron las acciones de la target.

h) Cláusulas varias.- En estas cláusulas suelen establecerse pactos como acuerdo de no competencia, acuerdo de no contratación del personal de la empresa target, lugar de las notificaciones, solución de controversias, entre otros puntos.

Toda esta estructura contractual, que puede parecer compleja y una mera copia del Common Law, tiene plena justificación, como ya lo he indicado, en la misma realidad que implica la venta de una empresa. En efecto, toda empresa es un fenómeno complejo que tiene innumerables factores, muchos de ellos desconocidos o inciertos que impactan en el valor de la misma. Recordemos que el adquirir las acciones de una empresa no implica sólo convertirse en accionista de la misma, sino además, trae consigo el asumir indirectamente los aspectos laborales, tributarios, contractuales, financieros, contables, entre otros.

Siguiendo lo antes señalado, el contrato de compra venta de acciones no sólo cumple la función de transferir las acciones del vendedor en la target sino además: a) Cumple la función de asignar riesgos entre el vendedor y el comprador estableciendo quién asume el riesgo en caso se materialice una contingencia producto de un hecho ocurrido con anterioridad a la transferencia de la empresa al comprador y b) Cumple la función de revelar información respecto de la situación de la empresa.

En esa función de revelar información, las declaraciones y garantías juegan un papel central pues si el vendedor no está dispuesto a otorgar una declaración estándar respecto, por ejemplo, de la inexistencia de procesos judiciales respecto de la target, entonces el comprador puede concluir que en ese aspecto podrían existir algunos riesgos que deben ser asignados entre las partes. 


\section{CAPÍTULO II: DE LAS DECLARACIONES Y GARANTÍAS}

\subsection{DECLARACIONES Y GARANTÍAS}

Las declaraciones y garantías son, en el Common Law que es de donde previenen, términos diferentes.

Las declaraciones en el derecho anglosajón (Representations) son afirmaciones respecto de hechos o situaciones de la target que permiten a un eventual comprador de acciones tomar la decisión de adquirirlas. De otro lado, las garantías (warranties) son aseveraciones respecto de la existencia de un hecho en particular y que tienen la particularidad que en caso una de esas garantías sea falsa o inexacta, el vendedor de las acciones de la target debería indemnizar al comprador.

Acorde con Ordónez Arias (2013), refiriéndose a la estructura de un contrato de compra venta de acciones elaborado bajo el modelo del Common Law:

La cláusula de declaraciones y garantías busca dar seguridad al negocio, en el entendido de que las partes podrán acceder a la indemnización pactada en caso que las manifestaciones hechas por la contraparte hayan sido incompletas o hayan faltado a la verdad. De esta forma, las declaraciones y garantías son una forma de garantizar a las partes que no existen otras contingencias o pasivos ocultos en la empresa cuyas acciones se están enajenado y que, en caso de haberlas, el contratante afectado podrá recurrir a la indemnización, sin perjuicio de lo que se verá más adelante respecto de la cláusula de limitación de responsabilidad. (p. 6)

En el derecho peruano, los términos declaraciones y garantías son usados como sinónimos y son afirmaciones respecto del estado societario, tributario, laboral, contable, financiero, entre otros, de la target. Además, en la legislación peruana, las declaraciones y garantías no están reguladas en ningún texto normativo. Por ello, a diferencia del Common Law, en la legislación peruana, las declaraciones y garantías por sí solas no generan mayor aporte pues para que sí aporte a una relación jurídica se les debe añadir las cláusulas de indemnización 
en virtud de las cuales en caso una de las declaraciones y garantías sea falsa o inexacta, el vendedor responderá por los daños y perjuicios que esa falsedad o inexactitud le haya generado al comprador o a la target.

La cláusula de declaraciones y garantías, tanto en el modelo anglosajón como en el modelo peruano, cumple las funciones de reducir los costos de transacción y asignar riesgos. La reducción de los costos de transacción se da pues si el vendedor otorgar las declaraciones y garantías y asume la responsabilidad por su falsedad o inexactitud, genera que el comprador decida celebrar el contrato de compra venta haciendo menos investigaciones o auditorías de las que debería realizar.

Normalmente, el comprador para acceder a la información de la target pedirá información a los vendedores y/o realizará un proceso de due diligence. En palabras del Boisset (2015), refiriéndose al proceso de due diligence y al pedido de información al vendedor, dice: "que dichos mecanismos no son suficientes; ya que tienen limitaciones propias de tiempo y otros costos de transacción que harían muy costoso que un comprador pueda acceder a toda la información que requiere" (p. 145)

Es aquí donde las declaraciones y garantías toman importancia pues para equilibrar esa asimetría en la información, el comprador le pide al vendedor que le otorgue tales declaraciones y garantías y que en caso una de esas sea inexacta o falsa; el vendedor de las acciones de la target debe indemnizar al comprador. Ello sin ninguna duda reduce los costos de transacción.

Respecto de la función de asignar riesgos, esta función se cumple pues el riesgo de la falsedad o inexactitud de una declaración y garantía es asumida por el vendedor, es decir, en caso de inexactitud o falsedad de una de ellas, se acuerda que el vendedor debe indemnizar al comprador.

Es pertinente mencionar que las declaraciones y garantías no son obligaciones contractuales pues no importan una obligación da hacer, no hacer o dar, sino son garantías contractuales accesorias de las demás obligaciones establecidas en el contrato de compra venta de acciones. Al no ser obligaciones contractuales, no debe analizarse si el vendedor al 
momento de emitir la declaración y garantía incurrió en culpa leve, negligencia grave o dolo, en ese sentido, basta para que el comprador tenga derecho a reclamar la indemnización que la declaración y garantía sea inexacta o falsa.

En palabras del Payet (2015):

La función de las declaraciones y garantías es actuar como verdadero mecanismo de aseguramiento. Cuando el vendedor asegura que la empresa es titular de las licencias administrativas necesarias para la operación de sus negocios, responde frente al comprador en caso de que la realidad se desvíe de lo afirmado. Ello es independiente de que el vendedor haya o no tenido conocimiento de la falsedad de su declaración. Esto es así porque las declaraciones y garantías no son obligaciones contractuales, sino situaciones fácticas que una de las partes asegura a la otra y por cuya inexistencia se compromete a indemnizarla. La declaración opera de esa manera como un aseguramiento de la cualidad prometida. De esta forma, el vendedor no requiere ser culpable - haber sabido o podido conocer la falsedad de la declaración para responder por ella. El vendedor responderá simplemente porque aseguró la existencia de una cualidad, asumiendo para sí el riesgo de su inexistencia y garantizando al comprador plena cobertura contra dicho riesgo. (p. 98)

Algunas modelos de declaraciones y garantías son los siguientes:

- Las obligaciones establecidas en el Contrato y su ejecución no violan ley vigente alguna, normas administrativas, resoluciones judiciales, laudos arbitrales o cualquier otra disposición legal aplicable a los Vendedores o a la Sociedad.

- No hay litigio, contingencia legal o a Conocimiento de los Vendedores, amenaza alguna contra los Vendedores o la Sociedad, ante órgano jurisdiccional, administrativo, arbitral, o Autoridad Gubernamental que limite o prohíba, se oponga o impida la suscripción del Contrato y/o el cumplimiento de las obligaciones que se generan en virtud del mismo.

- Las Acciones se encuentran totalmente suscritas y pagadas y sobre las mismas no pesa Gravamen, cargas o medidas judiciales o extrajudiciales de clase alguna, o derecho que restrinja o límite de modo alguno el derecho de libre disposición sobre las mismas. 
- Los Estados Financieros han sido preparados de acuerdo con los PCGA, sobre una base consistente con las políticas, prácticas y procedimientos contables de la Sociedad, métodos de valuación y los principios aplicados por ésta en años anteriores.

- La Sociedad ha presentado dentro de los plazos legales y en la forma requerida, las declaraciones juradas y demás formularios relevantes a que se encuentra obligada respecto de todos los tributos que la gravan, y ha declarado sus ingresos, ventas y servicios, y efectuado los pagos a cuenta y retenciones a que se encuentra obligada de acuerdo a ley, habiendo pagado oportunamente y en la forma debida todos los tributos y cargas a que se encuentra obligada.

- La Sociedad cumple con sus obligaciones contenidas en las leyes aplicables en materia laboral, pago de remuneraciones, beneficios sociales, aportaciones y contribuciones, incluyendo pero sin limitarse, al pago de horas extras e indemnización por descanso vacacional no gozado.

Como apreciamos, en ninguna de las declaraciones y garantías dada existe una conducta que implique una obligación de dar, hacer o no hacer. Por ello es que las declaraciones y garantías no pueden ser consideradas como obligaciones sino sólo garantías contractuales dadas por una de las partes y que son accesorias a las obligaciones establecidas en el contrato de compra venta de acciones.

En conclusión, las declaraciones y garantías son garantías contractuales dadas por el vendedor al comprador y que en caso una de esas declaraciones y garantías sea falsa, el vendedor deberá indemnizar al comprador, independientemente si el vendedor incurrió en culpa, negligencia grave o dolo. 


\section{CAPÍTULO III: DE LOS REMEDIOS POR LA VIOLACIÓN A LAS DECLARACIONES Y GARANTÍAS}

\subsection{Remedios de la legislación peruana a la falsedad o inexactitud de las declaraciones y garantías}

Tal como lo he mencionado, en este trabajo se analizará qué remedio legal establece el Código Civil peruano en caso de falsedad o inexactitud de las declaraciones y garantías. Este análisis es importante pues no se trata sólo de importar conceptos del Common Law y aplicarlo a los contratos de compra venta de acciones que se sujeten a la legislación peruana sino además, esos conceptos importados deben armonizar con la legislación peruana.

Es importante resaltar que las declaraciones y garantías al ser un instituto típico del Common Law no existe, en el código civil ni en ningún otro cuerpo normativo, ninguna regla específica regulando las declaraciones y garantías, lo que crea una serie de dudas respecto a la posibilidad de resolución, rescisión, anulación o nulidad producto de la violación de una declaración y garantías.

En nuestra opinión, existen dos figuras jurídicas establecidas en el código civil peruano que podrían ser un remedio contractual por la violación de una declaración y garantía.

\subsubsection{Error como vicios de la voluntad:}

El Código Civil peruano establece que en determinadas circunstancias la formación de la voluntad de los contratantes en un acto jurídico pudo haber sido afectada por factores externos que constituyen vicios de la voluntad. Dentro de esos vicios de la voluntad se encuentra el error. 
El Código Civil peruano no establece una definición de error. Por ello, debemos recurrir a la doctrina para obtener un concepto del mismo.

Según el Taboada Córdova (2002):

El error como vicio de la voluntad, consiste en una falsa representación de la realidad, que actúa como móvil o coeficiente determinante de la declaración de voluntad, afectando el mismo proceso de formación de la voluntad correctamente declarada. (p. 360)

Siguiendo esta definición dada por Taboada, en el supuesto de un contrato de compra venta de acciones, un comprador debería sostener que incurrió en error al celebrar el contrato de compra venta de acciones pues él consideraba que la sociedad tenía las cualidades señaladas por el vendedor en las declaraciones y garantías; sin embargo, esas declaraciones y garantías dadas eran inexactas o falsas, por ende, se hizo una falsa representación de la realidad. De tal manera, de haber conocido el comprador la inexactitud o falsedad de la declaración, el comprador no hubiese celebrado el contrato de compra venta de acciones.

Luego de señalado el posible argumento que utilizaría el comprador, corresponde ahora analizar si de acuerdo a los artículos del Código Civil que regulan el error como vicio de la voluntad, ante una violación a las declaraciones y garantías nos encontraríamos en un supuesto de error como vicio de la voluntad.

El artículo $201^{\circ}$ del Código Civil establece que "El error es causa de anulación del acto jurídico cuando sea esencial y conocible por la otra parte".

Sobre qué se entiende por esencial, el artículo $202^{\circ}$ del mismo código establece que:

El error es esencial:

1. Cuando recae sobre la propia esencia o una cualidad del objeto del acto que, de acuerdo con la apreciación general o en relación a las circunstancias debe considerarse determinante de la voluntad.

2. Cuando recae sobre las cualidades personales de la otra parte, siempre que aquéllas hayan sido determinantes de la voluntad.

3. Cuando el error de derecho haya sido la razón única y determinante del acto. 
Sobre qué se entiende por conocible, el artículo $203^{\circ}$ del Código Civil señala que "el error se considera conocible cuando, en relación al contenido, a las circunstancias del acto o a la calidad de las partes, una persona de normal diligencia hubiese podido advertirlo".

De las alternativas que nos da el artículo $202^{\circ}$ del Código Civil, el supuesto que podría resultar aplicable es el señalado en el inciso $1^{\circ}$.

Como se ha podido apreciar, el inciso $1^{\circ}$ señala que el error es esencial "cuando recae sobre la propia esencia o una cualidad del objeto del acto que, de acuerdo con la apreciación general o en relación a las circunstancias debe considerarse determinante de la voluntad".

De acuerdo a Lohmann Luca de Tena (2003), el objeto del acto se refiere al "asunto, tema o materia al que el negocio se refiere, o la cosa que es materia de la prestación" (p. 861)

De acuerdo a esa definición, en el caso de una compra venta de acciones, considero que más allá de que a través de una compra venta de acciones se adquiera toda la actividad empresarial de la empresa target, el objeto del acto jurídico son las acciones emitidas por la target.

Las declaraciones y garantías como se ha señalado son afirmaciones respecto de determinados aspectos de la target. Por ello, una declaración y garantía falta o inexacta no dará lugar a amparar la anulación del contrato de compra venta de acciones en base a la figura del error reconocida en el artículo $202^{\circ}$ del Código Civil pues las declaraciones y garantías no versan sobre el objeto del acto jurídico. Así lo entendió, el Tribunal Supremo en España en su sentencia del 21 de diciembre del 2009 dada en el marco de un proceso cuya pretensión fue declarar que el objeto del contrato de compra venta de acciones fue el inmueble donde operaba un hotel y no las acciones materia de compra. El Tribunal Supremo confirmó la sentencia de primera instancia la cual indicó que el objeto del contrato de compra venta de acciones eran las acciones y no el inmueble donde funcionaba el hotel. 
Sin perjuicio de lo señalado y usando el ejemplo señalado en el párrafo anterior, qué pasaría si en ese contrato se hubiera establecido que el objeto del mismo era adquirir las acciones de la target para así adquirir de manera indirecta la propiedad del inmueble donde opera el hotel. En este caso, considero que sería posible que un juez considere que el objeto del contrato eran no solo los inmuebles sino además las acciones.

Ahora, de ampararse la demanda por error, tal como se ha mencionado en el párrafo anterior, la solución que proporciona el Código Civil es la anulación del contrato de compra venta de acciones siendo su consecuencia que las acciones regresen a la esfera patrimonial del vendedor y este le devuelva al comprador el precio pagado. Esta situación es una situación indeseable pues el vendedor recuperará las acciones de una target que durante un tiempo fue operada por un tercero y por ende, la situación de la target puede ser muy distinta a la situación en la que la vendió.

En conclusión, el determinar si la inexactitud o falsedad de una declaración y garantía puede generar la anulación del contrato de compra venta en base al error como vicio de la voluntad es algo que debe analizarse caso por caso. En caso la inexactitud o falsedad de una declaración y garantía genere la anulación del acto por error, la solución que da el Código Civil es indeseable e implica costos muy elevados.

Un tema importante y que considero importante señalar es que en los contratos de compra venta de acciones se establece que el único remedio que tendrán las partes en caso de inexactitud o falsedad de las declaraciones y garantías es el pago de una indemnización. Es decir, de acuerdo al contrato de compra venta de acciones no se podría solicitar la anulación del contrato por causa del error. Esta imposibilidad implica una renuncia a la acción que se funde en error, dolo, violencia o intimidación, lo que está prohibido por el artículo $218^{\circ}$ del Código Civil.

Lo señalado en el párrafo anterior demuestra que no todo las cláusulas importadas del Common Law serían eficaces en el Perú, es decir, en ocasiones los acuerdos arribados por las partes no podrían ser ejecutados pues estaría en contra de normas imperativas establecidas en el Código Civil, de lo cual los abogados debemos de ser conscientes. 


\subsubsection{Vicios Ocultos:}

El artículo $1484^{\circ}$ del Código Civil indica que "hay lugar a saneamiento en los contratos relativos a la transferencia de la propiedad, la posesión o el uso del bien.”

Como se indicó, la venta de una target se instrumentaliza a través de un contrato de compra venta que es uno de los contratos por los cuales se transfiere la propiedad de un bien. Por ende, un contrato de compra venta de acciones podría dar lugar al saneamiento por evicción, vicio oculto o hechos propios.

En el caso de inexactitud de las declaraciones y garantías se plantea la duda sobre si la ocurrencia de una inexactitud de las declaraciones y garantías da lugar al saneamiento por vicio oculto.

El artículo $1503^{\circ}$ del Código Civil regula específicamente la figura del saneamiento por vicios ocultos. Dicho artículo establece que "el transferente está obligado al saneamiento por los vicios ocultos existentes al momento de la transferencia”.

Siguiendo lo señalado por los artículos $1503^{\circ}$, podemos sustentar que vicio oculto es toda imperfección existente sobre el bien transferido, que lo hace inadecuado para el propósito de su adquisición.

La relación del vicio oculto con las declaraciones y garantías es que un comprador puede argumentar que la obligación de saneamiento por vicio oculto tienen lugar en los casos de inexactitud o falsedad de una declaración y garantía pues a través de un contrato de compra venta de acciones se adquiere la empresa, lo que implica que se adquiere la realidad económica y jurídica de la empresa, por ende, cualquier falsedad o inexactitud en una declaración y garantía da lugar al saneamiento por vicio oculto.

En mi opinión, a través de un contrato de compra venta de acciones se adquiere la titularidad de las acciones emitidas por la target, por ende, la obligación de saneamiento recae directamente sobre esas acciones. En efecto, la obligación de saneamiento recae única y exclusivamente sobre el objeto del contrato y no sobre los aspectos accesorios del mismo. Baso mi posición en el artículo $1485^{\circ}$ del Código Civil que establece que: 
En virtud del saneamiento el transferente está obligado a responder frente al adquirente por la evicción, por los vicios ocultos del bien o por sus hechos propios, que no permitan destinar el bien transferido a la finalidad por la cual fue adquirido o que disminuye su valor.

Por lo expuesto, considero que hay lugar a saneamiento por vicio oculto sólo cuando el vicio recae sobre las acciones y no cuando recae sobre una violación a las declaraciones y garantías. Ampliar la aplicación del vicio oculto a los supuestos en que ocurra un caso de inexactitud o falsedad de una declaración y garantía es desnaturalizar el concepto de vicio oculto.

Además, una inexactitud o falsedad de una declaración y garantía de ninguna manera impiden darle a las acciones adquiridas el uso para el que están destinadas las acciones. Por ello, por ejemplo, la imposibilidad de usar un inmueble de una target para la finalidad deseada por el comprador, no dará lugar al vicio oculto toda vez que ese inmueble no fue materia del contrato de compra venta de acciones.

No obstante lo antes señalado, existe el artículo $1505^{\circ}$ del Código Civil que prescribe que hay lugar al saneamiento cuando el bien carece de las cualidades prometidas por el transferente que le daban valor o lo hacían apto para la finalidad de la adquisición.

Considero que alguien podría sostener que una violación a las declaraciones y garantías implica que las acciones de la target no tienen las cualidades prometidas. Es decir, el bien materia de la venta eran las acciones pero las mismas no tenían las cualidades indicadas en las declaraciones y garantías.

Ahora, la posibilidad de considerar como vicio oculto la violación de una declaración y garantía puede no ser muy útil para el comprador. Esto se debe a que el artículo $1514^{\circ}$ del Código Civil fija un plazo de caducidad de tres meses para iniciar las acciones legales por la violación de una declaración y garantía. Es prácticamente imposible que un comprador detecte dentro de un plazo de tres meses que una de las declaraciones y garantías es falsa o inexacta.

Otra de las consecuencias que implica considerar como vicio oculto la violación a una declaración y garantía es que el comprador de las acciones contará con dos remedios 
legales. El primer remedio es la acción redhibitoria la cual le permite al comprador solicitar la resolución del contrato de compra venta de acciones.

La resolución del contrato de compra venta de acciones trae como consecuencia que el vendedor vuelva a adquirir la titularidad de las acciones y que el vendedor le devuelva al comprador el precio pagado. Esta situación, tal como se ha mencionado para el caso del error, es una situación indeseable pues el vendedor recuperará las acciones de una target que durante un tiempo fue operada por un tercero y por ende, la situación de la target puede ser muy distinta a la situación en la que la vendió.

Además de ello, el valor que recibiría el comprador sería, de acuerdo al artículo $1512^{\circ}$ del Código Civil, inciso $1^{\circ}$, el valor que tendría el bien al momento de la resolución, si es que no existiera el vicio que lo afecta, teniendo en cuenta la finalidad de la adquisición. Esto implica que el comprador podría recibir como consecuencia de la resolución un importe inferior al que pagó pues el valor de la target pudo haber bajado.

El segundo remedio que ofrece el Código Civil es la acción estimatoria regulada en el artículo $1513^{\circ}$ del Código Civil. En virtud de este remedio, el comprador puede optar por pedir que se le pague lo que el bien vale de menos, por razón de vicio, en el momento de ejercerse la acción de pago, teniendo en cuenta la finalidad de su adquisición.

El remedio contemplado en el artículo $1513^{\circ}$ del Código Civil adolece del problema que el comprador podría recibir como indemnización un importe inferior al que pagó por las acciones pues el valor de la target pudo haber bajado.

En conclusión, podría ser posible, al amparo del artículo $1505^{\circ}$ del Código Civil, que la violación de una declaración y garantía sea considerada como vicio oculto; sin embargo, tanto para el comprador como para el vendedor, los remedios que ofrece el Código Civil son indeseables.

Por ello, tomando en cuenta que al amparo del artículo $1528^{\circ}$ del Código Civil se permite suprimir las obligaciones de saneamiento, salvo por el hecho propios, se hace necesario que las partes fijen en el contrato de compra venta de la target un régimen de garantías contractuales propio que remplace a las obligaciones de saneamiento, 
precisándose que ese régimen es el único aplicable en caso se presente una violación a las declaraciones y garantías.

Si no existiera esa supresión de la obligación de saneamiento por vicios ocultos, nuevamente el Código Civil supletoriamente otorgaría soluciones no deseadas por las partes en una operación de compra venta de acciones, de lo cual los abogados también debemos ser conscientes. 


\section{CAPÍTULO IV: LIMITACIÓN DE RESPONSABILIDAD POR LA VIOLACIÓN A LAS DECLARACIONES Y GARANTÍAS}

\subsection{Cláusula de limitación de responsabilidad en cuanto a monto en los contratos de compra venta de acciones en Perú}

Otra cláusula típica de un contrato de compra venta de acciones importado del Common Law y cuya validez dentro de la legislación peruana genera discusión, es la cláusula de limitación de responsabilidad en lo que respecta al monto por parte del vendedor en caso de violación de una de las declaraciones y garantías.

Tal como se ha mencionado, el contrato de compra venta de acciones cumple la función de asignar riesgos entre el comprador y vendedor. En estos tipos de contratos el comprador buscará que el vendedor asuma responsabilidad por todas las contingencias que puedan materializarse luego de celebrado el contrato de compra venta pero que tenga su origen en un acto u omisión ocurrido durante el periodo en que el vendedor era accionista. Por ese motivo, el vendedor emite las declaraciones y garantías afirmando que la target cumple con determinadas características, asumiendo así el riesgo de que una de ellas sea falsa o inexacta. Si se determina que una declaración y garantía es falta o inexacta, entonces el vendedor deberá indemnizar al comprador de acuerdo a los términos establecidos en el contrato.

En lo que respecta al vendedor, este tendrá el deseo de no tener responsabilidad por una empresa que ya no le pertenece y en todo caso de tenerla, buscará limitar su responsabilidad en cuanto a monto y tiempo. El asunto para el vendedor es muy claro, si tiene que asumir una responsabilidad ilimitada frente al comprador por la inexactitud de las declaraciones y garantías, el vendedor prefiere no vender. 
La marcada contraposición de intereses entre el vendedor y el comprador hace que la cláusula de límites de responsabilidad sea una de las cláusulas más negociadas durante una operación de M\&A.

La indemnización, con límites en cuanto a tiempo y monto, constituye el remedio que usualmente pactan comprador y vendedor en caso se presente la inexactitud o falsedad de una declaración y garantía.

De acuerdo a Rebaza Torres (2015):

Dentro de los aspectos indicados (refiriéndose a los aspectos usuales que se pactan respecto de la indemnización en un contrato de compra venta de acciones) se encuentran los límites vinculados a la cuantía del daño. $\mathrm{Al}$ respecto, las partes podrán pactar que para que un daño sea indemnizable el monto del mismo deberá ser igual o mayor, de forma individual o conjunta, a determinado monto. Estos límites están a la fijación de un monto mínimo individual que cada daño debe representar para ser objeto de indemnización, incluyendo incluso la posibilidad de sumar daños derivados de un mismo hecho, y/o a la fijación de un monto base que deberá ser superado por la sumatoria de daños individuales para que proceda su indemnización; la misma que, según el contrato, podrá pactarse por el exceso de este monto o desde el primer dólar correspondiente al daño sufrido.

Adicionalmente, la obligación de indemnización podrá limitarse a un monto máximo determinado; el mismo que equivaldrá al límite de responsabilidad del vendedor de conformidad con el contrato, determinando que de ser el caso, el comprador deba asumir el exceso de dicho monto.(68-69)

Lo indicado por Rebaza resume de manera general los pactos que las partes suelen acordar respecto de la indemnización a pagar por el vendedor al comprador en caso se presente una violación a las declaraciones y garantías.

A continuación, se describirá en qué consisten los acuerdos usuales a los que las partes suelen arriban en materia de indemnización en contratos de compra venta de acciones, los cuales, como he indicado, en su mayoría han sido resumidos por el Dr. Rebaza. 
Es importante notar que existen ciertas declaraciones y garantías que por su naturaleza de esenciales no están sujetas a ningún límite de responsabilidad. Estas declaraciones y garantías son las relacionadas a las acciones, la validez y eficacia del pacto social de la target, la capacidad de los vendedores, entre otras consideradas esenciales por el comprador.

Estos mecanismos los mencionaré en los literales a), b) y c) siguientes.

a) Monto Máximo $(C A P)$.-

Una de las modalidades usadas por las partes es fijar un monto máximo total de indemnización. Bajo esta modalidad, el vendedor sólo estará obligado a indemnizar al comprador por la violación de declaraciones y garantías hasta un monto máximo.

Ejemplo de este pacto es la siguiente cláusula:

Los Vendedores se obligan a pagar e indemnizar plenamente, mantener indemne y defender al Comprador, y sus respectivos sucesores y cesionarios por cualquiera y todas las Pérdidas sufridas o incurridas por parte del Comprador que surjan de o en relación con cualquier inexactitud o incumplimiento de cualquier declaración o garantía otorgada por los Vendedores.

Queda entendido que el Comprador no tendrá derecho a reclamar indemnización alguna a los Vendedores ni ésta tendrán obligación de efectuar compensación alguna al Comprador, por un monto superior al 5\% del Precio de Compra Definitivo (el Monto Máximo Indemnizable).

La lógica de establecer un monto máximo indemnizable pasa por el hecho que el vendedor no quiere verse expuesto a responder sin límite de monto por las contingencias que pueda tener la target. En efecto, si el vendedor respondiera sin límite de monto, se vería en la situación de haber vendido su empresa y además deberá indemnizar al comprador por montos que podrían ser superiores al precio de venta que ha recibido. Este límite de responsabilidad implica que el comprador debe asumir ciertos riesgos al celebrar el contrato de compra venta de acciones pues en caso se presente contingencias por importes superiores al límite fijado, ese exceso no podrá reclamarlo al vendedor. 


\section{b) Monto Mínimo Global (Basket).-}

A través de esta modalidad, las partes acuerdan que sólo procederá la indemnización a favor del comprador por violaciones a las declaraciones y garantías siempre que todas las reclamaciones sumen un monto mínimo predeterminado.

Este acuerdo se establece considerando que el vendedor no quiere someterse a reclamaciones por sumas muy bajas, de manera que resulte más costoso solicitar la indemnización que asumir el daño causado. Esto acuerdo también se debe a que toda target siempre presenta contingencias propias de sus actividades empresariales. Es prácticamente imposible encontrar una sola target que haya realizado actividad económica que no presente contingencias.

Una cláusula de este tipo se transcribe a continuación:

En relación con la responsabilidad por inexactitud y/o falsedad de las declaraciones y garantías, las Partes acuerdan que el Comprador sólo tendrá derecho a recibir indemnización por aquellas Pérdidas que en conjunto excedan la suma de US\$ 500,000.00 (Quinientos Mil y 00/100 Dólares de los Estados Unidos de América). Si no supera ese importe, el comprador no tendrá derecho a solicitar indemnización alguna.

Adicionalmente, en este tipo de cláusula se suele pactar si el comprador, una vez llegado el monto mínimo establecido, tiene el derecho a reclamar la indemnización desde el primer dólar o desde el dólar siguiente al límite establecido. Siguiendo nuestro modelo de cláusula, dependiendo lo acordado por las partes es posible que el comprador solicite la indemnización desde el primer dólar o es posible que el comprador solicite la indemnización desde el dólar US \$ 500,001.00 de tal forma que los primeros US \$ 500,000.00 no serán materia de indemnización.

De acuerdo a Amiel (2015), quien cita al Private Target Mergers \& Acquisitions Deal Points Study preparado por el comité de M\&A del American Bar Association (2013), en el que se concluyó, de las transacciones realizadas, que: (i) 
$89 \%$ contaban con un monto máximo indemnizable cuyo tope era menor al precio de compra;(ii) 5\% era igual al precio de compra; y, (iii) $4 \%$ no establecía un monto máximo indemnizable. En dicho estudio, también se concluyó que el medio promedio de montos máximos indemnizables de las transacciones analizadas equivalía aproximadamente al $10 \%$ del precio. (p. 130)

c) Monto mínimo por cada reclamo (Mini-Basket)

Este pacto consiste en fijar un monto mínimo que debe valer cada reclamación para poder acceder a la indemnización. Un ejemplo de esta cláusula es la siguiente:

Las Partes acuerdan que la vendedora estará obligada a indemnizar al Comprador respecto de los Daños Indemnizables que individualmente superen el monto de S/. 20,000.00 (Veinte Mil y 00/100 Nuevos Soles).

Esto quiere decir que si la reclamación individualmente considerada no supera la suma mínima pactada, el comprador no tendrá derecho a recibir la indemnización respectiva.

Es importante mencionar que pueden existir formas combinadas de establecer los mecanismos de indemnización. Por ejemplo, puede establecerse una cláusula de basket combinada con una cláusula mini basket tal como se muestra a continuación:

Las Partes acuerdan que la Vendedora estará obligada a indemnizar al Comprador respecto de los Daños Indemnizables que individualmente (superen el monto de S/. 20,000.00 (Veinte Mil y 00/100 Nuevos Soles) y que en conjunto superen el monto de S/. 50,000.00 (Cincuenta Mil y 00/100 Nuevos Soles) (el Monto Mínimo Indemnizable).

No es el propósito de esta parte del trabajo explicar todas las posibles formas en que las partes pueden regular los montos indemnizatorios, por ello, no se analizan todas esas formas posibles. 
Como se ha podido apreciar, todos los mecanismos que las partes suelen establecer en un contrato de compra venta de acciones respecto a la violación de las declaraciones y garantías tienen por finalidad limitar la responsabilidad del vendedor. Como se mencionó, el pacto de límite de responsabilidad es una importación del Common Law, por ello, es importante analizar si el mismo es válido de acuerdo a la legislación peruana la cual es muy celosa con el hecho de establecer límites a la responsabilidad de los contratantes.

Para estos efectos, debemos referirnos al artículo $1328^{\circ}$ del Código Civil, que establece que "Es nula toda estipulación que excluya o limite la responsabilidad por dolo o culpa inexcusable del deudor o de los terceros de quien este se valga".

El citado artículo se sitúa en la sección de inejecución de obligaciones del Código Civil. Las obligaciones importan la ejecución de una conducta por parte de las partes que podría consistir en una conducta de dar, hacer o no hacer.

Como hemos mencionado, las declaraciones y garantías no son obligaciones contractuales pues no importan una obligación da dar, hacer o no hacer; por ende, considero que la cláusula de limitación de responsabilidad en cuanto al monto por violación a las declaraciones y garantías es válida.

No obstante la validez de la cláusula de limitación de responsabilidad, en el caso que el vendedor haya emitido la declaración falsa o inexacta sabiendo que era falsa o inexacta, o debiendo haberlo sabido, considero que por el principio de la buena fe, la limitación establecida en los contratos de compra venta de acciones no sería aplicable en los casos de dolo o culpa inexcusable

En efecto, el artículo $1362^{\circ}$ del Código Civil establece que "Los contratos deben negociarse, celebrarse y ejecutarse según las reglas de la buena fe y común intención de las partes".

De acuerdo a de la Puente y Lavalle (2011): "la buena fe que el artículo $1362^{\circ}$ del Código Civil exige para la celebración del contrato determina que el 
oferente debe declarar lo que cree creer y el destinatario debe confiar razonablemente en esta declaración”. (p. 375)

Siendo así, si el vendedor de las acciones conocía la inexactitud o falsedad de las declaraciones y garantías o en debía conocerla, y a pesar de ello, emitió las declaraciones y garantías, entones esa limitación será ineficaz y el comprador tiene la vía expedita para solicitar el pago de una indemnización mayor al pactado en el contrato de compra venta de acciones.

Lo señalado en el párrafo precedente se produce debido a que en el Common Law sólo existe aquello establecido en el contrato mientras que en nuestro derecho civil existen normas imperativas que complementan los términos y condiciones establecidos en el contrato. Una de esas normas imperativas es el artículo $1362^{\circ}$ del Código Civil antes mencionado.

Esa ineficacia de la limitación de responsabilidad podría ser perjudicial para el vendedor pues su responsabilidad por el caso de negligencia grave no tendría límite de monto. No menciono el caso del dolo pues incluso en el Common Law si hubiera dolo no se respetaría el límite acordado.

Nuevamente nos encontramos en que los términos acordados en un contrato de compra venta de acciones podrían no tener la eficacia deseada por las partes. 


\section{CONCLUSIONES}

- La figura del error como vicio de la voluntad y el vicio oculto en principio no pueden ser empleadas en caso de violación de una declaración y garantía. Sin embargo, no descarto que existan casos que tengan que ser analizados detenidamente y que puedan ser amparados.

- No obstante ello, de ampararse una demanda de error como vicio de la voluntad o vicio oculto, la solución que otorga el Código Civil no es la más adecuada ni para el vendedor ni para el comprador. Además, a pesar que el contrato de compra venta establezca soluciones distintas a las establecidas por el Código Civil, las estipulaciones de dicho contrato no podrían ser aplicadas.

- Respecto a la limitación en cuanto al monto de responsabilidad en caso de violación a una declaración y garantía, es válida de acuerdo a la legislación peruana. Sin embargo, el principio de buena fe podría generar que sea ineficaz la inexactitud o falsedad de una declaración y garantía por culpa inexcusable del vendedor.

- El presente trabajo no ha buscado criticar la importación de conceptos del Common Law para la estructuración de contratos de compra venta de acciones bajo la legislación peruana. Todo lo contrario, considero que la estructura de los contratos de compra venta de acciones bajo el Common Law es la mejor manera hoy en día de celebrar dichos contratos. Sin embargo, es necesario ser conscientes de que las figuras del Common Law deben en ocasiones ajustarse para concordar con la regulación peruana o en todo caso algunos acuerdos propios de contratos de compra venta podrían no tener los efectos que las partes desean por más que sean los más apropiados para solucionar los conflictos.

- Lo señalado nos permite concluir que las partes de un contrato de compra venta de acciones regulan adecuadamente sus relaciones; sin embargo, normas del Código Civil podrían impedir que los acuerdos establecidos por las partes tengan eficacia. Ante ello, 
no suena descabellado plantear que para las operaciones comerciales, como las compra venta de acciones, no se aplique el principio de la buena fe pues llena a la operación de criterios impredecibles, discrecionales e incertidumbre, todo lo contrario que deben tener las relaciones comerciales. 


\section{REFERENCIAS}

Payet Puccio, J. A. (2015). Reflexiones sobre el Contrato de Compra Venta de Empresa y la Responsabilidad del Vendedor. Fusiones \& Adquisiciones, Lima: Instituto Peruano de Arbitraje.

Ordoñez Arias, P. (enero-junio 2013). Validez y efectos de cláusulas de limitación de responsabilidad en contratos de compra venta de acciones en Colombia. Revista de Derecho Privado, (49), Bogotá: Universidad de los Andes.

Boisset, R., (2015). Las declaraciones y aseveraciones: su relación con las obligaciones de indemnidad en los contratos de compra venta de acciones. Fusiones \& Adquisiciones, Lima: Instituto Peruano de Arbitraje.

Taboada Cordova, L. (2002) Acto Jurídico, Negocio Jurídico y Contrato, Lima: Grijley.

Lohmann Luca De Tema, G. (Marzo 2003). Código Civil Comentado, (1. a ed) [T. I], Lima: Editorial Gaceta Jurídica,

Rebaza Torres, A. (2015). Controversias Principales en Contratos de Compra Venta de Acciones. Fusiones \& Adquisiciones; Lima: Instituto Peruano de Arbitraje.

Amiel, S. (2015). Consideraciones Prácticas Respecto al Régimen de Indemnización en el Marco de una Compraventa de Acciones. Fusiones \& Adquisiciones; Lima: Instituto Peruano de Arbitraje.

De la Puente y Lavalle, M. (2011). El Contrato en General, [T. 1]. Lima: Palestra 


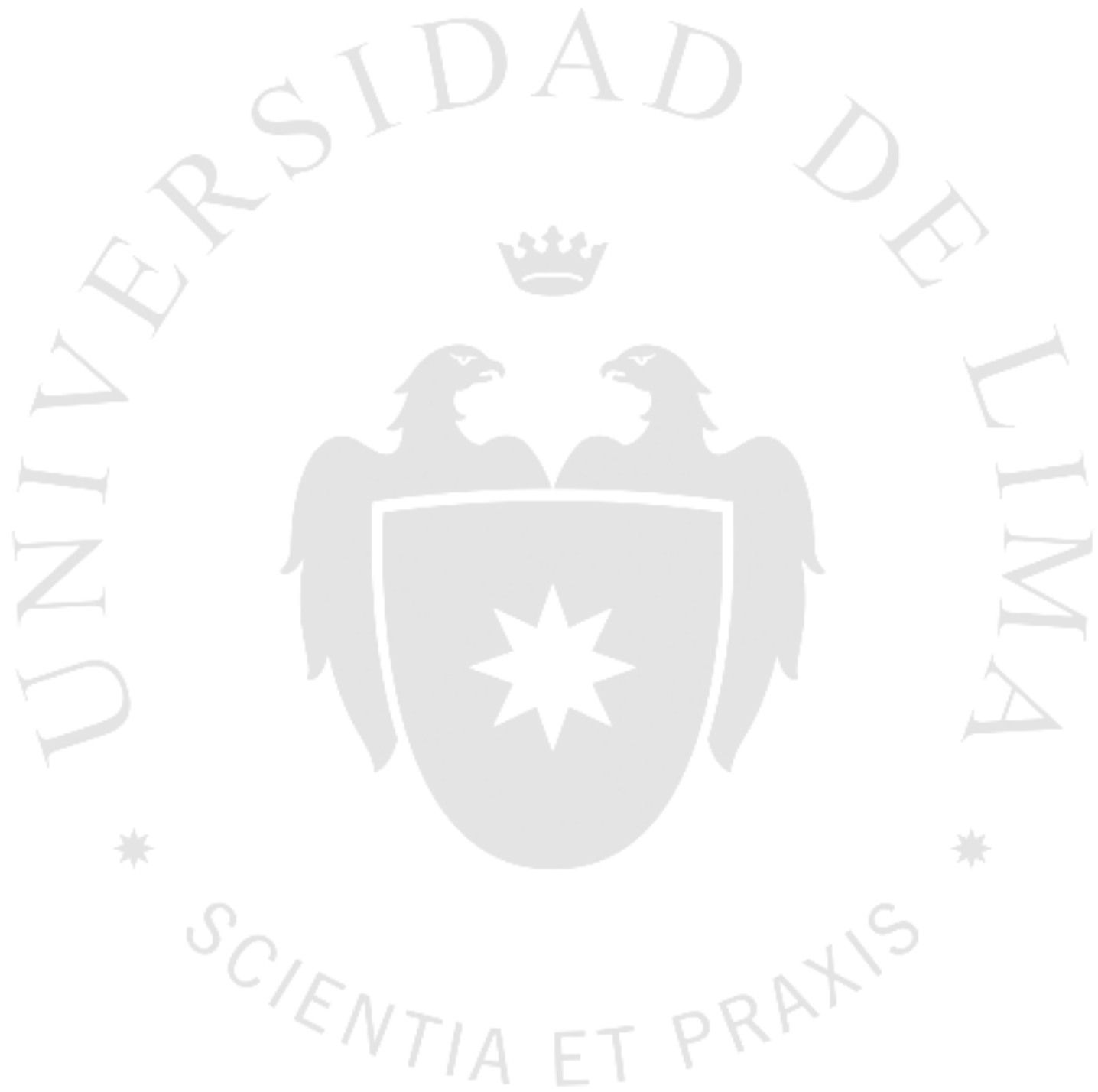

